\title{
The Comparative Analysis of External Heat Transfer Calculation Methods for a Solar Aircraft Spacesuit E.A. Rezanov ${ }^{1, \text { a) }}$, V.I. Merkulov ${ }^{1, \text { b) }}$, K.V. Rossova ${ }^{1, \mathrm{c})}$, I.V. Tishchenko ${ }^{1, \mathrm{~d})}$ \\ ${ }^{I}$ Bauman Moscow State Technical University, Moscow, Russian Federation \\ a) Corresponding author: rezanow.egor@yandex.ru \\ b) merkulov@bmstu.ru \\ c) ksen.rossova2011@yandex.ru \\ d) iv.tischenko@,bmstu.ru
}

\begin{abstract}
This article presents an assessment of the external thermal load on the life support system of a solar aircraft under extreme operating conditions. The calculation was carried out for the maximum and minimum possible heat flows in the key points of the aircraft flight. In this article the conditions on the Earth's surface and at the operating altitude of the aircraft were taken as calculated. The dependence of the quantitative changes in the heat load on the aircraft from altitude was revealed, taking into account changes of thermal properties of the environment and mechanisms of heat transfer.
\end{abstract}

Keywords: Renewable energy sources, solar plane, spacesuit, life support system, heat gain, heat balance.

\section{INTRODUCTION}

In recent years, renewable energy sources are gaining popularity due to deteriorating environmental situation trends and energy prices increase. The most affordable and versatile of all alternative energy sources is solar radiation. One of the most promising and illustrative ways of using it is a solar aircraft. This type of aircraft is in position to take a flight due using solar radiation, storing energy in batteries and gaining altitude during the day. The energy, which is stored during daylight hours is enough for a night flight, thus theoretically the flight time of such an aircraft is not limited. Successful launches of such projects by foreign companies confirm the possibility of successful operation of solar aircraft.

The design of this kind of aircraft requires a special approach due to the specificity of operation. One of the most acute problems is ensuring the vital activity of the aircraft crew. Due to the low cargo capacity of the plane, some solar aircraft models do not have a pressurized cabin. In this case, the entire burden of ensuring the conditions necessary for human life falls on the individual life support system.

The operating mode of the aircraft's flight involves ascent to an altitude of $25 \mathrm{~km}$. Thus, the pilot's life support system must provide comfortable conditions for controlling the aircraft not only near the Earth's surface, but also in the stratosphere, 
where the air density is about $2.5 \%$ of the earth's, which can be considered conditions close to space.

The present work consists of the comparative analysis of methods for calculating the external heat balance of a cosmonaut's space suit in the Earth's orbit and an object in the atmosphere near the Earth's surface.

\section{METHODS \\ Spacesuit analysis in outer space}

The method for the external heat balance analysis of a spacesuit in a space environment has the following assumptions [1]:

A) The outer surface of the spacesuit is isothermal $\left(T_{1}=\right.$ const $)$, since the perceived radiant fluxes are distributed fairly evenly over the shell of the spacesuit due to the constant movement of a person around the aircraft, and the aircraft's movement around the Earth and the Sun.

B) The thermal regime is permanent, since the package of the spacesuit shells has both low mass and heat capacity.

C) The temperature of the inner shell of the spacesuit $T_{2}$ is constant and is equal to the average temperature of the ventilating gas in the space under the spacesuit.

D) The surface of the aircraft is isothermal.

E) There is no convective heat transfer.

The thermal control of the space suit of a cosmonaut in the open space is contingent on the influence of such heat fluxes as:

1. Direct solar radiation $\left(Q_{\mathrm{S}}\right)$.

2. The aircraft's own thermal radiation $\left(Q_{\mathrm{v}}\right)$.

3. Earth's own thermal radiation $\left(Q_{\mathrm{e}}\right)$.

4. Heat radiation reflected by the aircraft $\left(Q_{\mathrm{vr}}\right)$.

5. Thermal radiation reflected by the Earth $\left(Q_{\mathrm{E} r}\right)$.

6. The heat radiated by the spacesuit $\left(Q_{\mathrm{r}}\right)$. 


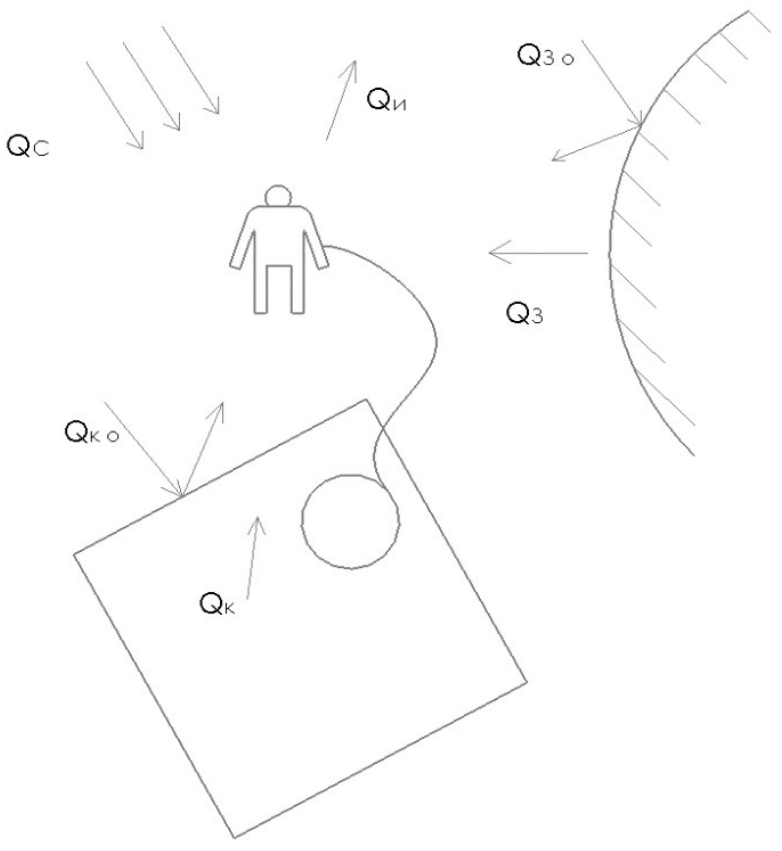

Figure 1. External heat exchange of the space suit

Analysis of heat fluxes by this method is carried out in accordance with the sequence described in the literature [1]. At the same time, light-toned phenylone fabric is taken as the material for the spacesuit casing. Flight altitude $-25 \mathrm{~km}$. The calculation is presented for two extreme cases: the highest and lowest heat load values.

\section{Case A:}

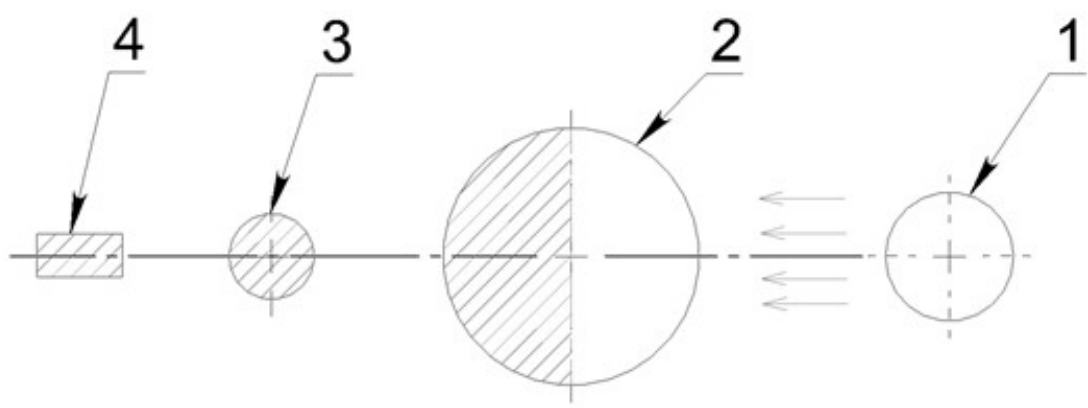

Figure 2. Case A. 1 - Sun; 2 - Earth; 3 - ship; 4 - a spacesuit;

The ship and the spacesuit are in the shadow of the Earth. The longitudinal axis of the spacesuit is directed radially to the Earth and perpendicular to the axis of the ship. The spacesuit is located between the ship and the Earth at the maximum 
distance from the ship, which is provided for by the work program. At a considerable distance from the ship, for example, with the assistance of the AMU of the cosmonaut, the ship does not have a significant thermal effect on the heat balance of the spacesuit $\varphi_{\mathrm{s}-\mathrm{e}}^{\prime}=0$, since the illuminated part of the Earth's disk is not visible from the point of spacesuit location. Then the total heat input into the spacesuit interior is the sum of $Q_{e}+Q_{\mathrm{s}}$, and the formula for $Q_{\mathrm{p}}$ takes the following form:

$$
Q_{\mathrm{p}}=\varphi_{\mathrm{S}-\mathrm{E}} \varepsilon E_{\mathrm{e}} F_{\mathrm{s}}+\varphi_{\mathrm{s}-\mathrm{s}} c_{0} \varepsilon \varepsilon_{\mathrm{s}}\left(\frac{T_{\mathrm{s}}}{100}\right)^{4} F_{\mathrm{s}}-c_{0} \varepsilon\left(\frac{T_{1}}{100}\right)^{4} F_{\mathrm{S}}
$$

where $Q_{\mathrm{p}}-$ the heat, penetrating inside the spacesuit, W;

$\varphi_{\mathrm{s}-\mathrm{e}}-$ the coefficient of mutual irradiation of the spacesuit and the Earth; $\varepsilon$ - emissivity factor of the spacesuit surface;

$E_{\mathrm{e}}-$ the Earth's radiant heat flux, $\frac{\mathrm{W}}{\mathrm{m}^{2}}$;

$F_{\mathrm{s}}-$ outer surface area of the suit, m;

$\varphi_{\text {s-s }}-$ the coefficient of mutual irradiation of the spacesuit and the ship;

$c_{0}-$ blackbody coefficient, $\frac{W}{\mathrm{~m}^{2} * \mathrm{~K}^{4}} ;$

$\varepsilon_{\mathrm{S}}-$ emissivity factor of the ship;

$T_{\mathrm{S}}$ - skin temperature of the ship, K;

$\varphi_{\mathrm{s}-\mathrm{e}}^{\prime}-$ coefficient of mutual irradiation of the spacesuit and the surface of the Earth, which is illuminated by the Sun.

\section{Case B:}

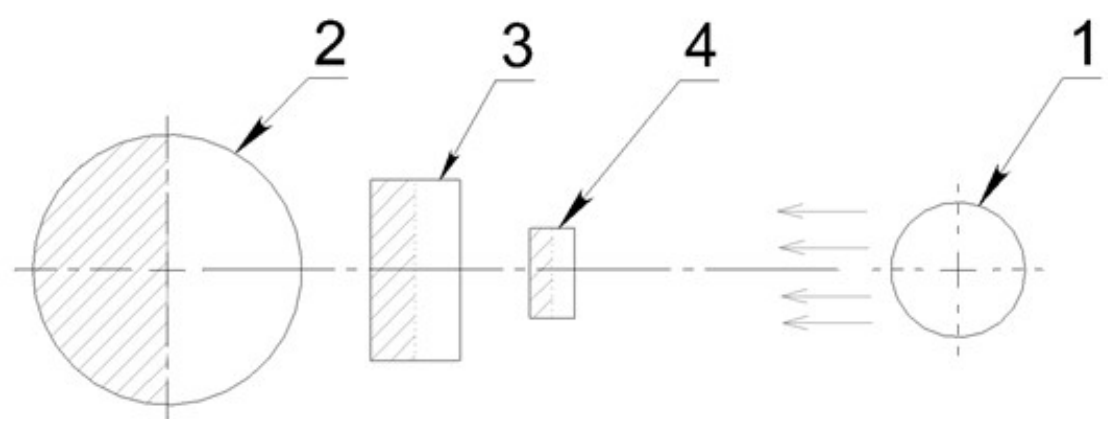

Figure 3. Case B. 1 - Sun; 2 - Earth; 3 - ship; 4 - a spacesuit;

The spacesuit is in an illuminated orbit on the line connecting the centres of the Earth and the Sun. Its axis is perpendicular to the radius of the Earth and the rays of the Sun. The spacecraft is located at a considerable distance from the spacesuit and does not obscure the direct and reflected solar radiation from the Earth. The value of $T_{\mathrm{s}}$ is not to large, and the cosmonaut himself is so far from the spacecraft, so that $Q_{\mathrm{s}}$ can 
be neglected. In this case, the load on the suit is determined by $Q_{\mathrm{S}}, Q_{\mathrm{E}}$ and $Q_{\mathrm{E} \mathrm{r}}$. It's obvious that $\varphi_{\mathrm{s}-\mathrm{e}}^{\prime}=\varphi_{\mathrm{s}-\mathrm{e}}$, and $\varphi_{\mathrm{s}-\mathrm{s}} \cong 0$. Then, $Q_{\mathrm{p}}$ could be found as follows:

$$
Q_{p}=\frac{A_{s} J_{0} F_{\mathrm{s}}}{\pi}+\varphi_{s-e} \varepsilon E_{e} F_{\mathrm{s}}+\varphi_{\mathrm{s}-\mathrm{e}} A_{s} A_{E} J_{0} F_{S}-c_{0} \varepsilon\left(\frac{T_{1}}{100}\right)^{4} F_{S}
$$

where $A_{S}$ - the outer shell of the spacesuit solar utilization factor;

$J_{0}$ - the solar constant, $\frac{\mathrm{W}}{\mathrm{m}^{2}}$;

$A_{\mathrm{E}}-$ Earth albedo.

\section{Analysis of an object near the surface of the Earth}

The thermal mode of an object, which is located in the Earth's atmosphere, immediately close to its surface is influenced by the heat flows, which are considered in the literature [5]:

1. Convection heat transfer $\left(Q_{\text {conv }}\right)$.

2. Normal beam solar radiation $\left(Q_{S}\right)$.

3. Diffuse solar radiation $\left(Q_{\mathrm{d}}\right)$.

4. Atmospheric back radiation $\left(Q_{\mathrm{a}}\right)$.

5. Earth's self - radiation $\left(Q_{\mathrm{E}}\right)$.

6. Earth's self back heat radiation return $\left(Q_{\mathrm{E} \mathrm{r}}\right)$.

7. Atmospheric back radiation $\left(Q_{\mathrm{a}} \mathrm{r}\right)$.

8. Object heat radiation $\left(Q_{r}\right)$.

The object is located at noon in an open area on a clear day with cloudless weather. Two critical cases are considered - winter and summer.

$$
Q_{p}=Q_{r l}+\alpha_{\mathrm{h}} F_{s}\left(T_{1}-T_{a m b}\right)-c_{0} \varepsilon\left(\frac{T_{1}}{100}\right)^{4} F_{\mathrm{s}}
$$

where $Q_{\mathrm{r} \text { l }}$ - total radiation load on the compartment;

$\alpha_{h}$ - heat-exchange coefficient $\frac{\mathrm{W}}{\mathrm{m}^{2} * \mathrm{~K}} ;$

$T_{a m b}$ - ambient air temperature.

\section{COMPARATIVE ANALYSIS OF THE METHODS FOR CALCULATING THE EXTERNAL HEAT EXCHANGE OF THE SPACESUIT}

\section{Referent Criterion}

The criteria for comparing methods for the calculating external heat transfer is the fundamental difference in the effect of different methods of heat transfer in calculation methods, which are used for different external conditions. 


\section{Original Observations}

The initial data for the first method calculation - is the outer temperatures of the ship and the spacesuit, the material of the spacesuit shell, as well as the optical characteristics of the ship's skin described in [1].

The initial data for the second method calculation - is the data from climatic reference books [11], the material of the spacesuit shell, so as the weather conditions.

\section{RESULTS AND DISCUSSION}

As a result, the calculation indicated as per below:

- Convection has a significant effect on the external heat exchange within the conditions of the Earth's atmosphere: depending on the initial conditions, the winter heat outflow, due to convection heat exchange, could possibly exceed the total radiation load in 2.25 times at zero wind speed. In summer conditions, convection heat gain is commensurate with the effect of radiation load;

- Depending on the conditions, the heat load on the spacesuit could be either positive or negative. During the design process of the life support systems, it is necessary to take into account the variability of the external effect on the thermal balance and to protect the aircraft pilot from both overheating and hypothermia;

- An important way to regulate the heat load, which is perceived by a spacesuit in a rarefied space, is to change the material of its shell. By changing the optical characteristics, it is possible to achieve the optimal value of heat gain during cruise flight. With a decrease in flight altitude, this method loses its effectiveness due to an increase in the role of convection in heat transfer.

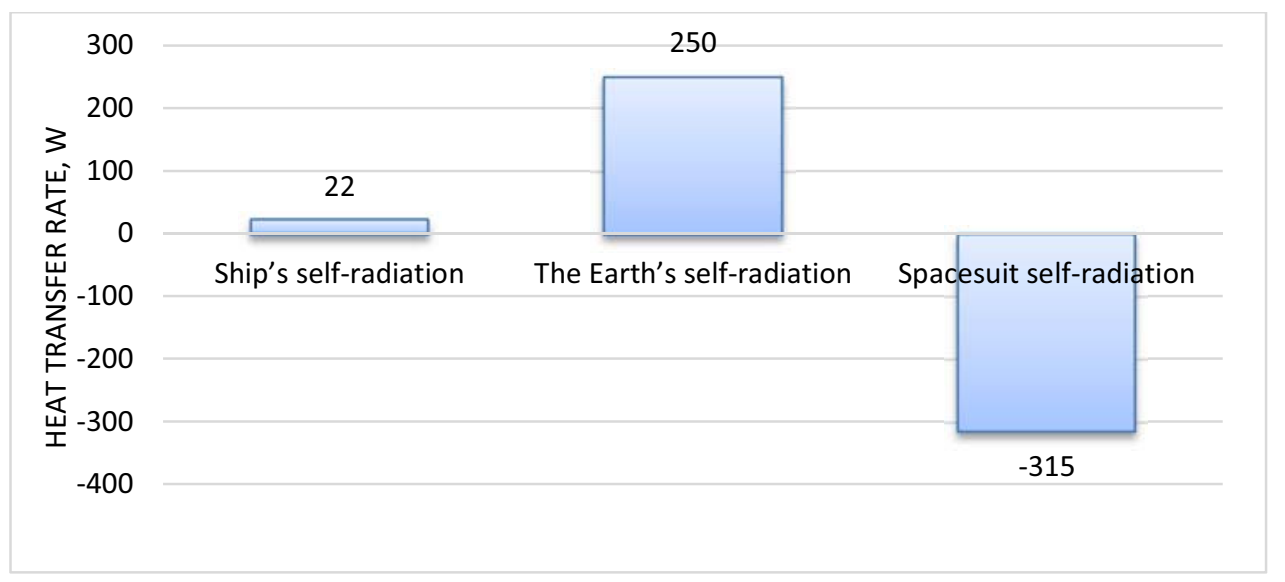

Table 1. Minimum heat gains in space conditions. Case A. 


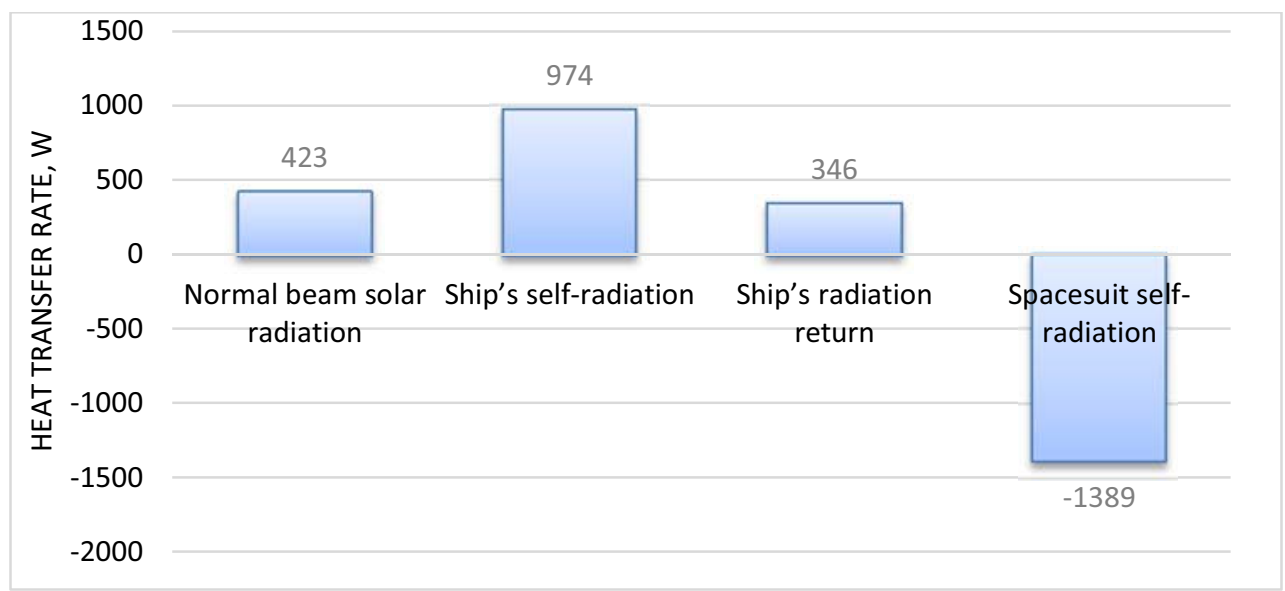

Table 2. Maximum heat gains in space. Case A.

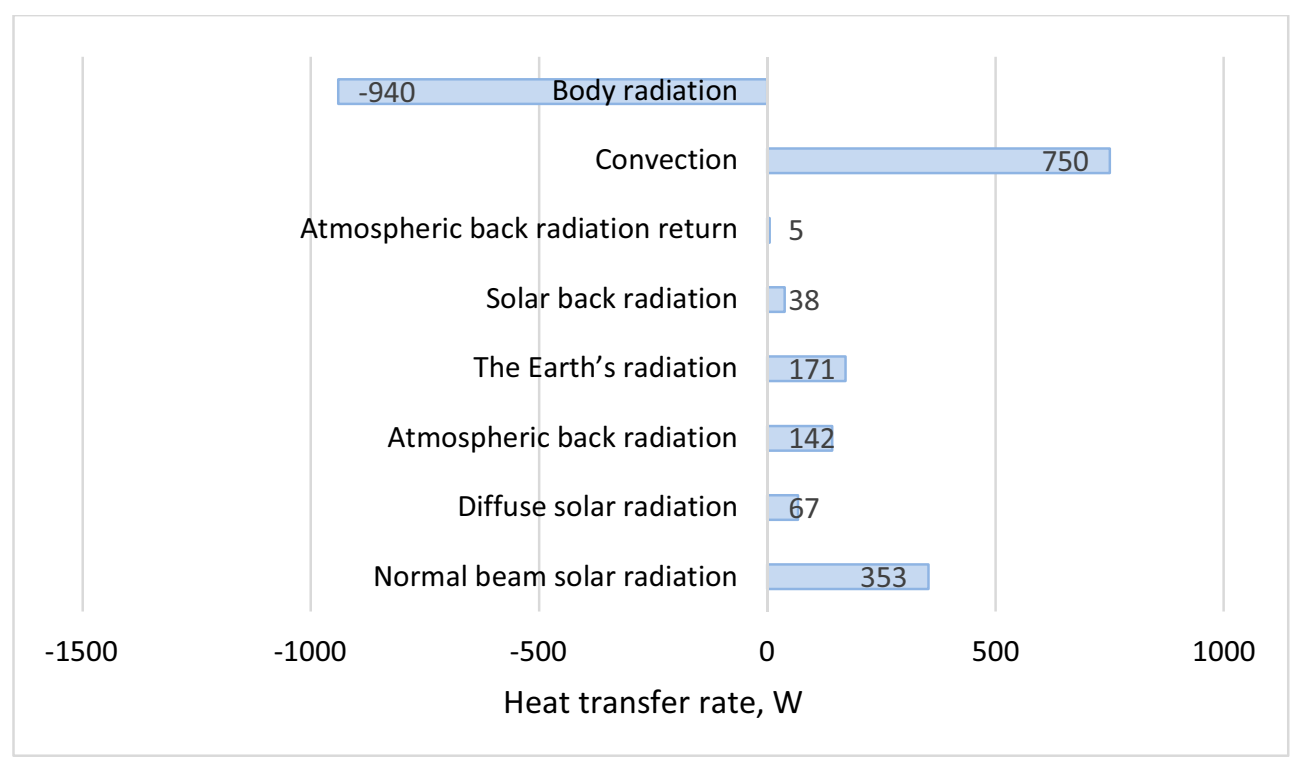

Table 3. Maximum heat gains at the ground surface in summer conditions. 


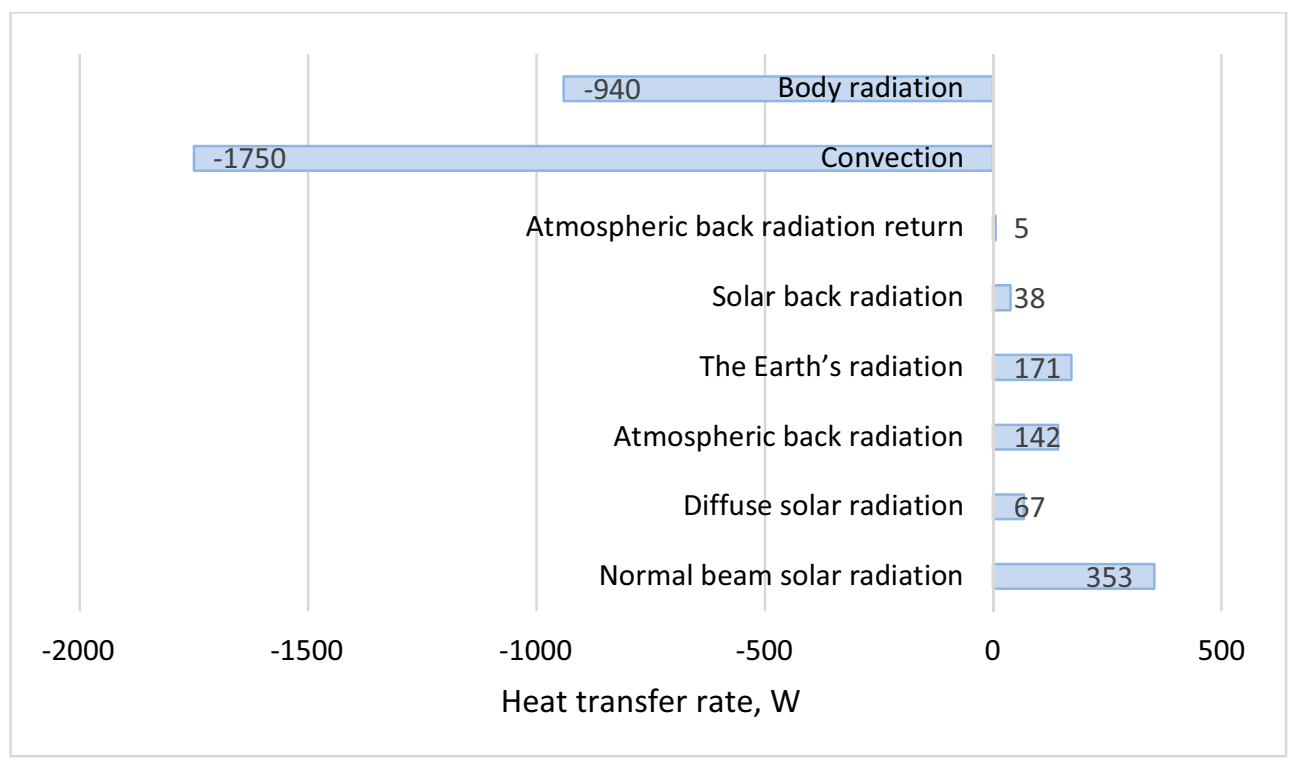

Table 4. Minimum heat gains at the ground surface in winter conditions.

\section{CONCLUSION}

For the considered flight mode of a solar aircraft (height of ascent - $25 \mathrm{~km}$ ), the heat load on the pilot's spacesuit would continuously change as the aircraft ascends. The calculation methods, which are used to determine the heat balance at the initial stage of the flight and upon reaching the cruising altitude, take fundamentally different assumptions. So, it does not give us accurate results for the entire flight period. For a more complete and accurate analysis of the heat load on the spacesuit of a pilot of a solar aircraft with a nonpressurized cabin, it is necessary to develop a method that takes into account all quantitative and qualitative changes in the environment throughout the flight, which could be as a topic for further research.

\section{REFERENCES}

1. I.P. Abramov, G.I. Severin, A.U. Stoklitsky, R.Kh. Sharipov Space suits and systems for EVA. - M.: Mashinostroenie, 1984. - 256 p.

2. K.Ya. Kondratyev Radiant heat exchange in the atmosphere. - Leningrad: Gidrometeoizdat, 1956. -- 421 p.

3. K.Ya. Kondratyev Radiant Sun Energy. - Leningrad: Gidrometeoizdat, 1954. -600 p.

4. K.Ya. Kondratyev, L. N. Dyachenko and V. V. Kozoderov, 1988, The Earth's Radiation Budget, Leningrad, Gidrometeoizdat, 1988. - 350 p.

5. M. I. Budyko The Heat balance of the Earth's surface. - Leningrad:

Gidrometeoizdat, 1956. -- 255 p. 
6. Kuo-Nan Liou. Basics of radiation processes in the atmosphere. Gidrometeoizdat, Leningrad, 1984. - p. 376.

7. L.T. Matveev The Course of General Meteorology. Physics of the atmosphere. - 4th ed. - Leningrad: Gidrometeoizdat, 1984. -- 751 p.

8. D.I. Ivanov, A.I. Khromushkin Human life support systems for high-altitude and space flights. - M.: Mashinostroenie, 1968. -- 252 p.

9. V.F. Rozhnov Space life support systems. - M.: MAI, 2009. -- 344 p.

10. Alekseev S.M., Umansky S.P. High-altitude and space suits. - M.: Mashinostroenie, 1973. -- $280 \mathrm{p}$.

11. Scientific Application Handbook on the USSR Climate. Issue 19. Uzbekskaya SSR. Book 2. - Leningrad: Gidrometeoizdat, 1989. - 350 p.

12. Voronin G.I., Polivoda A.I. Life support for spacecraft crews. - M.: Mashinostroenie, 1967. -- $212 \mathrm{p}$.

13. Life support systems for aircraft crews. Textbook for technical colleges. V.V. V.F. Malozemov, V.N. Rozhnov, Pravetsky. - M.: Mashinostroenie, 1986, $584 \mathrm{p}$.

14. V.N. Serebryakov Principles of Design of Systems for Life Support of Spacecraft Crew. - M.: Mashinostroenie, 1983, - 160 p.

15. I.A. Arkharov, E.S. Navasardyan, M.V. Simakov MICROCRYOGENIC GAS MACHINES IN STRATEGIC SATELLITE NAVIGATION, SURVEILLANCE, AND COMMUNICATIONS SYSTEMS - Chemical and Petroleum Engineering. 2016. V. 51. № 11-12. P. 765-770.

16. S.S. Chugaev, E.M. Strizhenov, A.A. Zherdev, R.A. Kuznetsov, Podchufarov A.A., Zhidkov D.A. FIRE- AND EXPLOSION-SAFE LOWTEMPERATURE FILLING OF AN ADSORPTION NATURAL GAS STORAGE SYSTEM - Chemical and Petroleum Engineering. 2017. V. 52. № 11-12. P. 846-854.

17. A.Y. Vshivkov, A.V. Delkov, A.A. Kishkin, N.A. Lavrov FIRST TERRESTRIAL TESTS AT LIQUID HE TEMPERATURE OF SPACE APPARATUS PASSIVE THERMAL PROTECTION - Chemical and Petroleum Engineering. 2019. V. 54. № 9-10. P. 746-750.

18. A.V. Delkov, A.A. Kishkin, N.A. Lavrov, F.V Tanasienko. ANALYSIS OF EFFICIENCY OF SYSTEMS FOR CONTROL OF THE THERMAL REGIME OF SPACECRAFT - Chemical and Petroleum Engineering. 2016. V. 51. № 9. P. 714-719.

19. A.A. Kazakova, Y.V. Nikiforov, B.K. Zuev PILOT STUDY OF DESORPTION KINETICS OF ADSORBATE FROM AN ADSORBENT GRANULE - Chemical and Petroleum Engineering. 2015. V. 51. № 1. P. 8488. 